\title{
BOG TOXINS AND THEIR EFFECT UPON SOILS ${ }^{\mathrm{T}}$
}

\author{
ALFRED DACHNOWSI \\ (WITH TWO FIGURES)
}

In the north and in the middle west, notably in Indiana and Illinois, and to some extent in Ohio and the adjoining states, there are extensive swamp areas of vast importance to the state, some of which are called "unproductive," and generally are not cultivated. The statement is made, and there is certainly much truth in it, that these swamp lands should be naturally very rich in constituents needed for plant food. Many of these places represent deep basins of accumulated plant débris, and the drainage from hills further enriches the accumulation in the swamps. They are noted for their dense and luxuriant surface vegetation. Examples of swamp and bog areas in this vicinity show clearly that bog water contains apparently all of the constituents required for the nutrition, growth, and reproduction of a large variety of grasses, shrubs, and trees. However, from an agricultural point of view these muck and swamp lands seldom have given satisfaction, even after drainage or addition of fertilizers. Ample proof of this is seen in the reports of the various experiment stations $(\mathbf{7}, \mathbf{8})$. Thus far the remedies proposed, as a laboratory expedient, emphasize the fact that although some principles of soil fertility seem well established, and can be applied with definite results, there are yet many complex problems, the solution of which would materially enhance the economic importance of peat and swamp soils.

To the writer it has seemed probable for some time that work upon the chemistry and upon the physiological properties of peat and humus compounds must result in data valuable alike to the agriculturist, the forester, and the ecologist. Through an investigation on the cause of xerophily in bogs (5), there was gained supplementary evidence, of a more direct and positive sort, that the inhibiting factors of a bog are in part the presence in the soil water of injurious toxic sub-

I Contribution from the Botanical Laboratory of Ohio State University, XLIII. This paper was in part read before Section G of the A.A.A.S., at the Baltimore meeting, December 29, I908. 
stances. In that publication experimental data were given to show that the toxicity of bog water and of the bog-soil substratum can be corrected by various methods, and that the plants grown in solutions thus treated show not only accelerated growth and an increase in transpiration, but also an increase in the green and dry weight of organic matter.

It is not known, as yet, whether the toxic action of bog water and bog soil is determined by the action of one constituent or by the combined action of several. The experiments so far completed have given no definite evidence that the toxins are merely specific excretions from the roots and rhizomes of bog plants. Preliminary tests, not here detailed, which were carried on in the winter of 1907 , indicate that the toxicity may be due to a certain unstable body, of the nature of organic compounds excreted from the roots in the absence of $\mathrm{O}_{2}$ and in heavy clay soils not adequately aerated. It is probably a product of imperfect oxidation and decomposition of proteins and other related substances, and it is possible that in respiration bog plants differ from other plants. Since then an excellent account has appeared by Stoklasa (12), in which similar results on the excretions by roots are announced. Largely, however, the toxicity of bog water seems to be due to another cause. During the changes which the accumulated plant material undergoes in the process of peat-making, there are alterations and reductions leading to gaseous and colloidal products but little known. The relative amount of these varies with the seasons, and no doubt also with the locality, but primarily it depends upon the stage in the progress of decomposition. $\mathrm{CH}_{4}$ and $\mathrm{H}_{2} \mathrm{~S}$, though produced in small quantities, have been found to constitute the principal gaseous products. They are especially noticeable when well-corked jars of bog water remain standing for some time. Studies on the character of the colloidal products are still in progress. The injurious products of a microflora accumulating in definite layers of the soil are, perhaps, an additional factor to be considered. Indeed, it is a serious difficulty in physiological ecology that a process must be assigned to a single category or broken up into a number of what often prove to be arbitrary categories, in order to arrive at results in any way intelligible. Too often is there a tendency to lay undue emphasis upon "average" 
conditions; and the more detailed responses which are due to localized influences are thus neglected. On the other hand, even though we decide experimentally which of the physical and chemical variables involved is of greater influence at a given stage, it still remains to determine how the ensemble of factors acts in the process which accompanies each physiographic change and serves as the functioning basis for morphological differences.

In connection with the experiments on the presence of injurious substances in bog water and bog soils, and their effect upon agricultural plants, the question arose whether the toxins which are harmful to plants in water cultures are injurious also to plants growing in soil containing them. This question has an added interest just now, because facts like those cited above give indications that the sterility of unproductive and "exhausted" agricultural soils may partly be caused by some toxic substance of a similar physiological and chemical origin. Different workers have observed that the growth of plants often gives rise to unfavorable conditions. The data obtained from various lines of experiments all go to prove that "exhaustion" cannot always be attributed to the removal of plantnutrients from the soil by previous crops or by previous plant societies (I0). To attempt a review of the literature on this problem would be out of place in the present paper. Suffice it to say that the results thus far obtained point strongly to the view that decreased physiological activity of plants lies rather in the toxic condition of the soil. The experimental proof is still regarded by many as furnishing negative evidence upon the problem $(6,9)$, and hence a spirit of controversy prevails in most of the writings upon this subject. However, it can no longer be questioned that the solution of this inquiry is of great importance to agriculture. It promises to throw new light upon many interrelations of soil and plants, and appears to afford a satisfactory explanation of some of the problems connected with the association and succession of plants, which on every other criterion would largely remain an enigma.

For the purpose of determining whether the toxins of bog water are harmful also to plants growing in soils containing the injurious substances, it was decided to employ first of all a soil medium as nearly non-nutrient as possible. Quartz is one of the chief and most 
nearly insoluble constituents of soil. It has been shown (2) that quartz is of minor importance in the adsorption and retention of hydroxids and various neutral salts; a knowledge of its action for bog water seemed, therefore, of fundamental importance. The quartz used was obtained from the Ceramics Department of the university. To free it from possible impurity it was subjected to a thorough washing. The air-dry quartz sand was first sifted through a sieve having meshes of $\mathrm{I}^{\mathrm{mm}}$. Portions of about $25^{\mathrm{gm}}$ of the sifterl material were each placed in a large porcelain dish containing distilled water acidulated with $\mathrm{HCl}$. It was usually the practice to boil the material for twenty minutes. After boiling, the supernatant liquid was decanted and fresh distilled water was added. A similar washing was carried out in aqua regia and later again in dilute $\mathrm{KOH}$. The quartz was then washed repeatedly in boiling distilled water and finally dried at $100^{\circ} \mathrm{C}$ until ready for use.

The bog water used in these experiments was collected from the same central station on the bog island as described in the earlier paper. The solution is relatively clear, the suspended particles imparting to it a slight tinge of olive green to brown. It is very little acid to phenolphthalein, but alkaline to methyl urange.

Since no experiments had been made thus far to ascertain how much of the toxic property of bog water is removed by a given quantity of an adsorbing agent, series of ten cultures were prepared for this purpose. Seven of the cultures consisted each of $4{ }^{\circ 0^{c c}}$ of bog water, to which was added sterilized quartz in quantities equivalent to the following volumes: $25,50,75,100,125,150$, and $200^{\circ c}$ respectively; that is, the quantities were chosen in volumes equal to a definite fraction of the volume of bog water used. The bog water and the quartz sand were shaken together in glass-stoppered bottles, and left standing for several days. When ready for use the liquid was decanted and placed in half-liter Mason jars, corered with black paper. Three control cultures were added, consisting respectively of untreated bog water, boiled bog water, and distilled water. The wheat seedlings used for these cultures were germinated in sawdust until 4 to $5^{\mathrm{cm}}$ high. In later experiments the seedlings were germinated in quartz sand. They were then carefully washed in distilled water and transplanted to the water cultures. Never less than six 
seedlings were used in any experiment. It should be observed also that the seedlings were selected individuals out of a large number of plants. The corks used were previously sterilized and paraffined. Growth was measured by transpiration and the green and dry weight of plants. The cultures stood side by side in the university greenhouse in diffused light. The weekly atmometer readings varied between $\mathrm{I} 76$ and $\mathrm{I} 86^{\mathrm{cc}}$. Below are given toxicity figures for bog water collected at two periods. Column I gives data for bog water collected September I2, I908, nearly at the end of one of the most severe droughts that have been experienced in Ohio; the bog water for column II was brought to the laboratory October 16 , soon after the first rains. The evidence derived from similar experiments with bog water collected at intervals of one month during the year is omitted, showing, as it does, considerable repetition. It should be noted, however, that the variation in the range of results for the seasons is considerable.

\section{TABLE I}

ADSORPTION OF BOG TOXINS BY QUARTZ SAND

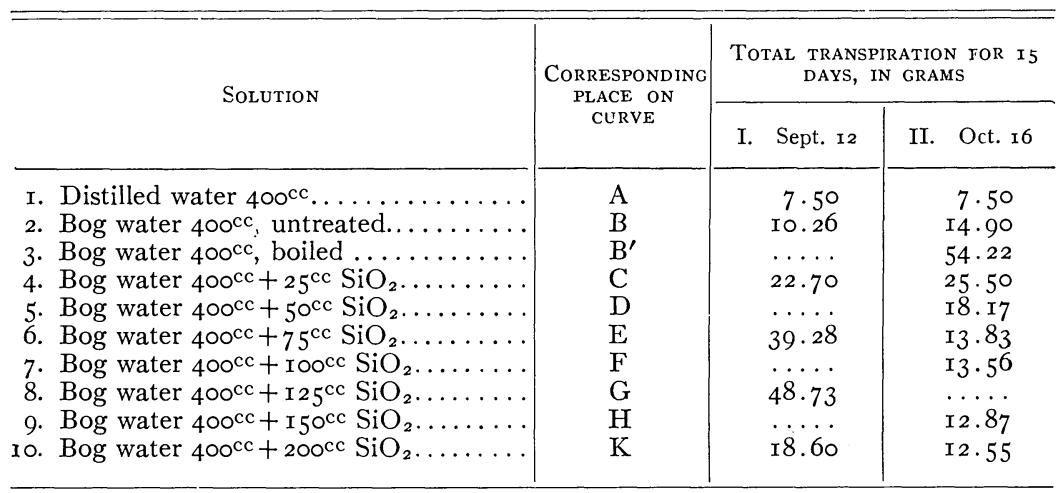

The results for these two dates have been plotted in fig. $I$. The growth-rate in terms of transpiration is indicated on the axis of ordinates, and the progressive addition of quartz to bog water is shown on the axis of abscissas.

Before taking up the facts brought out in this series of experiments, another part of the investigation must be mentioned here. The foregoing observations suggested the query whether results obtained with soils of varying quality, fineness, and adsorbing surface would 
show that the toxic strengths of the same bog-water solution have approximately the same relation to each other irrespective of the nature of the filter used. It was intended to use types of soil ranging progressively through the weathering products from feldspars to kaolin. But the feldspars are highly alterable minerals, and the chemical products of feldspathic and granitic rock-decomposition

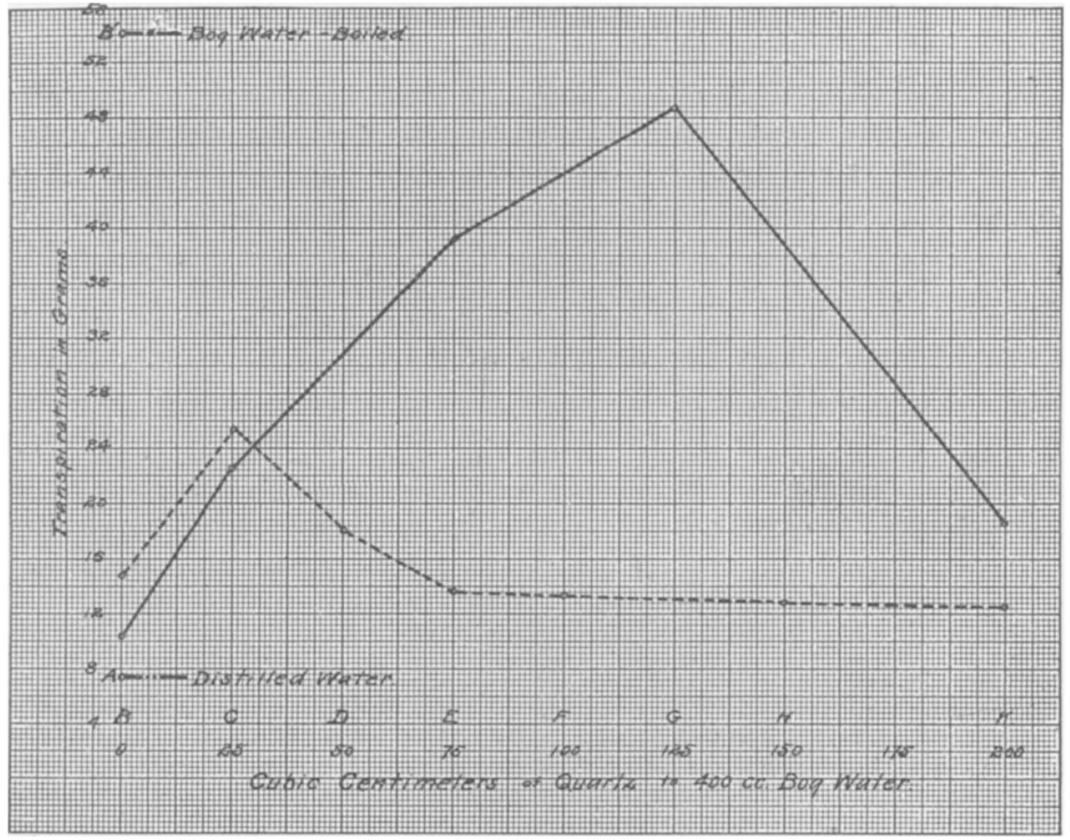

FIG. r.-Diagram showing growth-rate of wheat seedlings in treated bog water. The ordinates represent transpiration in grams; the abscissas show the progressive addition of quartz to bog water. Unbroken lines for bog water collected September I 2, I908. Broken lines for bog water of October 16, I908. Broken line single dotted for boiled bog water; broken line double dotted for distilled water.

are extremely varied (4). In the residues, however, which remain after leaching, free silica as quartz, and a number of rather indefinite substances known as clays, are the most abundant. In the present case the efficiency of the following substances, characteristir of the final residue of soil-forming rocks, and their allied substances, was tested: $\mathrm{SiO}_{2}$ coarse; $\mathrm{SiO}_{2}$ fine; kaolin; $\mathrm{CaCO}_{3} ; \mathrm{SiC}$; and $\mathrm{C}$ in the form of air-dried humus. The materials were obtained through 
the courtesy of Mr. C. H. KerR of the Carborundum Company, Niagara Falls, New York. They are among the most insoluble substances known, and of great purity, which makes them of special value in this investigation. The chemical analysis of these materials is as follows:

TABLE II

\begin{tabular}{|c|c|c|c|}
\hline Material & Quartz & Kaolin & Carborundum \\
\hline 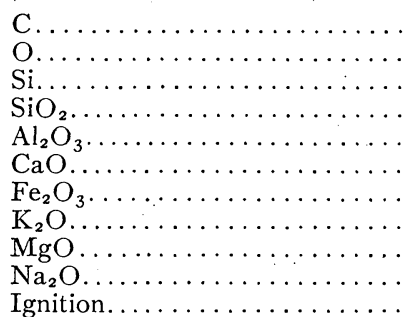 & $\begin{array}{l}\ldots \ldots \\
\ldots \ldots \\
\ldots \ldots \\
99 \cdot 5^{6} \\
0.40 \\
\cdots \cdots \\
\ldots \cdots \\
\ldots \cdots \\
\cdots \cdots \\
\text { O.14 }\end{array}$ & $\begin{array}{r}\cdots \\
\cdots \cdots \\
\cdots \cdots \\
45.35 \\
38.86 \\
0.35 \\
0.38 \\
0.61 \\
0.3 \mathrm{I} \\
0.3 \mathrm{I} \\
\mathrm{I} 3.80\end{array}$ & $\begin{array}{r}29 \cdot 7 \mathrm{I} \\
0.45 \\
69.40 \\
\cdots \cdots \\
0.28 \\
0.15 \\
\ldots \ldots \\
\ldots \ldots \\
0.05 \\
\ldots \ldots\end{array}$ \\
\hline
\end{tabular}

The physical composition of the materials employed was determined by microscopic examination. Mechanical analysis was made with the aid of a centrifuge and for the coarser components by means of their different rates of subsidence in water. The relative percentages by weight of the different component particles in each group is as follows:

TABLE III

\begin{tabular}{l|c|c|c|c}
\hline \multicolumn{1}{c}{ Material } & $\mathrm{SiO}_{2}$ coarse & $\mathrm{SiO}_{2}$ fine & Kaolin & $\mathrm{SiC}$ \\
\hline $\begin{array}{l}\text { Sand } \\
\quad 0.5-0.25^{\mathrm{mm}} \ldots \ldots \ldots \ldots \ldots\end{array}$ & $\mathrm{IO0}$ & $\ldots$ & $\ldots$ & $\ldots$ \\
$\begin{array}{l}\text { Very fine sand } \\
\quad 0 . \mathrm{I}-0.05^{\mathrm{mm}} \ldots \ldots \ldots \ldots\end{array}$ & $\ldots$ & 6.5 & 2.4 & 79.4 \\
$\begin{array}{l}\text { Silt } \\
\quad 0.05-0.005^{\mathrm{mm}} \ldots \ldots \ldots \ldots\end{array}$ & $\ldots$ & 80.8 & $6 \mathrm{r} .8$ & $\mathrm{I} 6.6$ \\
$\begin{array}{l}\text { Clay } \\
0.005-0.0 \mathrm{~mm} \ldots \ldots \ldots \ldots\end{array}$ & $\ldots$ & $\mathrm{I} 2.9$ & 35.7 & 4.5 \\
\hline
\end{tabular}

To obtain the surface area of spherical particles it is only necessary to invert the value of the mean diameter of the particles for each group. This surface factor is then multiplied by the fractional amount of the quantity of the sample having particles of these mean diameters. A mathematical calculation of the surface area of quartz flour, carborundum, or other crystalline bodies with irregular 
surfaces, however, is not so readily obtained. It may be that adsorption of toxins and adsorption of vapors and gases are subject to the same conditions (II). Perhaps by taking measurements upon the rate of retention of a silver salt, one may secure an indirect method for the calculation of the surface of these bodies. A curve showing how the adsorption data are related to the surface presented by the grains of the different soils used, though of interest, is not a question at issue in this discussion, but it is hoped to continue this problem further, and in a more quantitative manner.

The precaution was taken to allow contact between the solution and the solid bodies for thirty minutes only, in order to reduce to a minimum the low solubility of the materials (3) and the possible action of the solution upon the solids. The amounts used in each case, and the effect of these insoluble substances on the toxic action of bog water collected January 30, I909, are given below in Table IV. The transpiration data cover a period of fifteen days and are for six wheat plants in each solution.

TABLE IV

ADSORPTION OF BOG TOXINS BY INSOLUBLE SUBSTANCES

\begin{tabular}{|c|c|c|c|c|}
\hline \multirow{2}{*}{ Solution } & \multicolumn{4}{|c|}{$\begin{array}{c}\text { T'RANSPIRATION IN GRAMS; } \\
\text { SIX WHEAT SEEDLINGS IN EACH SOLUTION }\end{array}$} \\
\hline & $5^{\text {th }}$ day & roth day & I5th day & Total \\
\hline I. Bog water $400^{c c}$, untreated. & $4 \cdot 30$ & 8.55 & 3.65 & I6. 50 \\
\hline 2. Bog water $400^{c c}$, filtered.. & $4 \cdot 90$ & 10.35 & 6.75 & 22.00 \\
\hline 3. Bog water $400^{c c}+I_{5}{ }^{c c} \mathrm{SiO}_{2}$ (coarse). & $5 \cdot 25$ & I0.00 & $7 \cdot 35$ & 22.60 \\
\hline 4. Bog water $400^{c c}+25^{\mathrm{cc}} \mathrm{SiO}_{2}$ (coarse). & $7 \cdot 20$ & I 2.85 & 9.80 & 29.85 \\
\hline 5. Bog water $400^{c c}+50^{c c} \mathrm{SiO}_{2}$ (coarse). & 7.00 & $\mathrm{I} 3 \cdot 55$ & I0. 65 & $3 \mathrm{I} .20$ \\
\hline 6. Bog water $400^{c c}+I^{c c} \mathrm{SiO}_{2}$ (fine).. & 8.60 & I9. I0 & I3. 50 & $4 \mathrm{I} .20$ \\
\hline 7. Bog water $400^{c c}+25^{c c ~} \mathrm{SiO}_{2}$ (fine).. & 6.70 & $\mathrm{r} 9.00$ & 16.60 & $42 \cdot 30$ \\
\hline 8. Bog water $400^{c c}+5^{c c} \mathrm{SiO}_{2}$ (fine).. & 7.68 & I6.40 & I3. IO & $37 \cdot 18$ \\
\hline 9. Bog water $400^{c c}+15^{c c}$ Kaolin.... & 9. ro & 20.00 & 16.25 & $45 \cdot 35$ \\
\hline Io. Bog water $400^{c c}+25^{\text {cc }}$ Kaolin... & 9.65 & $19 \cdot 32$ & $21 \cdot 58$ & 50.55 \\
\hline II. Bog water $400^{c c}+50^{c c}$ Kaolin. & 9.95 & 20.10 & $23 \cdot 40$ & $53 \cdot 45$ \\
\hline I2. Bog water $400^{c c}+15^{\circ c c}$ Kaolin. & II. 98 & 22.20 & I6.07 & 50.25 \\
\hline I3. Bog water $400^{c c}+\mathrm{I}_{5}{ }^{\mathrm{cc}} \mathrm{CaCo}_{3}$. & 10.90 & 20.50 & $24 \cdot 70$ & 56.10 \\
\hline I4. Bog water $400^{c c}+25^{c c} \mathrm{CaCo}_{3}$. & 10.48 & 20.70 & 26.50 & 57.68 \\
\hline 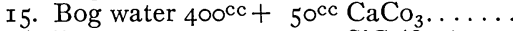 & 10.07 & I9. I7 & $23 \cdot 35$ & $5^{2} \cdot 5^{2}$ \\
\hline I6. Bog water $400^{c c}+{ }^{2} 5^{c c} \mathrm{SiC}$ (fine).. & II .23 & $2 \mathrm{I} .25$ & 25.60 & 58.08 \\
\hline I7. Bog water $400^{c c}+25^{\text {cc }} \mathrm{SiC}$ (fine).. & 10.90 & I7. $50^{*}$ & $21.20 *$ & $48.60 *$ \\
\hline I8. Bog water $400^{c c}+5^{c c} \mathrm{SiC}$ (fine). & II . 25 & 23.00 & 29.10 & 63.60 \\
\hline I9. Bog water $400^{c c}+I^{\text {cc }}$ C. (humus). & II . 00 & $25 \cdot I_{5}$ & 40.65 & $7^{6} .80$ \\
\hline 20. Bog water $400^{c c}+25^{\text {cc }}$ C. (humus). & $8 \cdot 30$ & I6.70 & 41.90 & 66.90 \\
\hline 21. Bog water $400^{c c}+\mathrm{I}_{5} \mathrm{occ}^{\mathrm{cc}} \mathrm{C}$. (humus). & 8.55 & $22 . x_{5}$ & 24.80 & $55 \cdot 50$ \\
\hline
\end{tabular}

* 5 plants in culture. 
Several facts seem to be clearly brought out in the above data. A comparison of the toxicity figures of bog water collected at intervals during the year indicates that the amount of toxic substances in solution differs very appreciably within the year. In all cases the physiological studies show that the adsorbing substances actually remove definite quantities of bog toxins. In contrasting the efficiency of the various amounts of adsorbents used, the important facts at the outset are these. Different physiological phases result from the progressive increase of an adsorbing substance. The bog-water solution, fatal in its effect at some seasons, gives an increase in growth-rate when adsorption removes a sufficient amount of the toxic ingredient. The effect is virtually one of dilution. Doubling of the amount of the adsorbent brings the growth-rate into a physiological phase marked by a greater functional activity. Further addition and its consequent further dilution in toxicity carries with it a corresponding intensification in growth-rate. The appearance of the plants, especially in the development of the root system, follows the transpiration figures very closely (see 5, figs. $1,4-5$, p. I35). Stimulation and tolerance rise to a maximum. But with successively larger amounts of adsorbent, the optimum rate of transpiration can be neither increased nor maintained. It falls off, regularly and rapidly at first, subsequently less rapidly, until the effect of the solution is practically that of distilled water (13). Greater dilution and consequent increase in rate of transpiration does not express therefore the whole truth. Other and less injurious substances are also adsorbed; and the rate of transpiration is seen to be the product of a coordination of factors ( $\mathbf{I}$ ). In bog water with very slight toxicity, the course of the experiment shows that the maximum acceleration phase deviates very sensibly toward the growth-rate approximated in the control i. e., the untreated bog water.

On account of the difference in size of particles, there naturally follows a corresponding difference in the amount of adsorption. Compared with kaolin, calcium carbonate, carborundum, and carbon (as lampblack or humus), the adsorptive power of quartz is relatively low. It will be seen that the optimum rate of transpiration of the tenth day, in solutions 3 to 8 , Table IV, is soon succeeded by a minimum. This is due to the action of toxic substances still 
present; for upon further addition of adsorbents the minimum at the end of the fifteenth day is succeeded by a higher rate of transpiration. Filters of finer grain are more beneficial, while the adsorptive power of humus is very much higher than that of any of the crystalline substances used. The optimum and maximum rates of transpiration occur on the fifteenth and twentieth day and lie near together. Reference to the total amount transpired shows that the adsorption of carborundum and humus is about three to four times greater than that of quartz. The transpiration data serve excellently as a basis for assigning a limit to the magnitude of the toxic effect, and as an expression of the amount of the unknown body adsorbed both in terms of the total adsorption, and as a percentage of the surface factor of grains. The results with $\mathrm{CaCO}_{3}$ also show that the plants are not affected by conditions of acidity or alkalinity, and that growth seems to be more materially affected by the specific action of the organic toxins present. Whatever the nature of the filter used, that the increased tolerance of wheat seedlings to bog water is actually due to the adsorptive power of the filters is sustained by the fact that the decrease of the poisonous effects of bog water is apparently a function of surface of particles and is approximately proportionate to the quantity of the solid body used. The solution, decidedly toxic without the solid, becomes capable of supporting a more than normal growth.

The outcome of these preliminary tests is, therefore, that the conditions giving rise to decreased physiological activity, to xerophily, and to zonation of bog plants are not found in the depletion or increase of mineral nutrients in bog water, nor in a low soil temperature, but lie rather in the toxicity of the soil substratum, i. e., in the production of unfavorable soil conditions brought about by the plants themselves.

However, experiments by the water-culture method may not always be serviceable as a safe basis for argument concerning soil conditions. A number of life relations of the plant in a water culture become changed when in the soil. In what particular manner the toxic bodies are held by the adsorptive force of the filters is not clear if judged by physical or chemical analysis. The marked retention of the toxins of bog water observed may be due to causes other than a direct condensation on the surface. No experiments were made to 
show conclusively that the retention is not due to chemical fixation or substitution. The amount of solution thrown out of the quartz by the centrifugal machine was too small to be tested. A priori, it would seem that the filter used should be markedly more toxic now than the solution, when tested by physiological criteria. The presence of the adsorbed bodies in the solid should not only reduce its effectiveness when repeatedly used for improving bog water, but should replace normal growth by an abnormal retardation judged from the growth-rate made in a similar check soil culture.

To obtain evidence on this point, and to contrast the efficiency of the various constituents of agricultural soils for adsorption, a series of experiments was made with quartz, river sand, field clay, and humus soil. The air-dry soils were sifted through a sieve with meshes of $\mathrm{I}^{\mathrm{mm}}$. Portions of $400^{\mathrm{cc}}$ of the sifted soils were each placed in glass-stoppered jars containing $\mathrm{I} 200^{\mathrm{cc}}$ of bog water. The glassware employed in all of the experiments cited was treated with a solution of potassium dichromate and sulfuric acid, and repeatedly rinsed in distilled water previous to use. The mixtures of bog water and soil were left standing in the dark room for three days. To insure thorough contact between the bog water and the soil, the solution was occasionally shaken. When ready for use the liquid was filtered off, and portions of $400^{c c}$ of the liquid from each soil type were used as water-culture experiments in the manner described above. For the investigation on the relative fertility of the soils used as filters, earthenware pots were used. The pots were new and each of about $300^{c c}$ capacity ( $8^{\mathrm{cm}}$ in diameter, $8.5^{\mathrm{cm}}$ deep). They were thoroughly cleaned and dried in an oven at $110^{\circ} \mathrm{C}$, and later immersed in heated paraffin. To each paraffined pot was added $200^{\mathrm{cc}}$ of the contaminated soil well pressed into the bottom and sides of the pots. It was recognized that difficulties of obtaining good contact between the soil and the walls of the pot would be probable. In the air space along the walls usually by far the greater proportion of plant roots are developed, and the wire-basket method as recommended by the Bureau of Soils of the U. S. Department of Agriculture (Bull. 23) is, therefore, more desirable. But the form of retainer here described was found to be wholly satisfactory. In no case were evidences found of roots growing more freely at the sides of the pot than in the center. The experi- 
ments were repeated later by the wire-basket method with the same results. Six wheat seedlings were transplanted in a row in the soil of each pot. In identically the same manner a series of duplicate cultures with the untreated soils was prepared to serve for comparison with the behavior of wheat seedlings in the contaminated soils. The filled pots were then weighed and placed in the greenhouse where they stood side by side. Direct sunlight was avoided by cloth screens. Only one of the experiments need be given, and Table $\mathrm{V}$ gives a summary of the results obtained with bog water collected September I2, I908. The percentage increase is calculated upon the basis of the quantities marked zero (o), considering them as unity for the respective series. The photograph (fig. 2), which I owe to the aid of Professor J. H. Schaffner, shows these plants at the end of the experiment.

TABLE V

ADSORPTION OF BOG TOXINS BY SOILS

\begin{tabular}{|c|c|c|c|c|c|}
\hline \multirow{2}{*}{ Solution } & \multicolumn{2}{|c|}{ AVERAGE LENGTH IN CM. } & \multicolumn{3}{|c|}{ Percentage increase } \\
\hline & Tops & Roots & Transpiration & Green weight & Dry weight \\
\hline I. Bog water untreated.. & I 5.8 & $5 \cdot 3$ & o & 0 & $\circ$ \\
\hline 2. Bog water quartz-filtered... & 20.8 & 42 & 338 . & I34. & 56. \\
\hline 5. Bog water clay-filtered... & I9.9 & II 4 & I 54. & 68 & II. \\
\hline 8. Bog water humus-filtered. & 30.5 & I 5.6 & 805 . & 220. & 84 . \\
\hline 3. Contaminated quartz soil. & 22 . & I $2 \cdot 3$ & $\ldots$ & o & 0 \\
\hline 6. Contaminated clay soil. & 22.2 & 6.6 & $\ldots$ & $\circ$ & o \\
\hline 9. Contaminated humus soil... & $2 I .9$ & 6.2 & . & 0 & o \\
\hline 4. Control quartz soil........ & $24 \cdot 7$ & 9.6 & . & 8. & 20 . \\
\hline 7. Control clay soil.... & 26 . & II. 7 & $\ldots$ & $2 \hat{\jmath}$. & 5 \\
\hline ro. Control humus soil. . & 30.7 & I $3 \cdot 5$ & . & 86. & 55 . \\
\hline
\end{tabular}

Again it is evident that the addition of solids has increased the tolerance of the seedlings to bog water. The improvement was marked during the entire period of experimentation. The presence of the toxic bodies in small amounts exerted a noticeable stimulating effect, while the plants in the control bog water gave every indication that they would be unable to survive an exposure of a normal growing period. The last-mentioned point has been repeatedly tested also in field-work. It seems as if the roots, and especially the more minute roothairs, of the plants in the untreated bog water served as adsorbing surfaces. The roots are brownish in color and jelly-like in consist- 
ency; deposited upon their surfaces are found numerous colored bodies, as the result of the oxidizing action of the roots. The nature of these bodies is still under investigation. A general decay of the growing tips is noticeable, showing that the oxidizing action of the plants upon the toxic substances went far toward decreasing their harmful effect, but could not entirely overcome them. The effectiveness of adding the insoluble solids proves, therefore, very conclusively

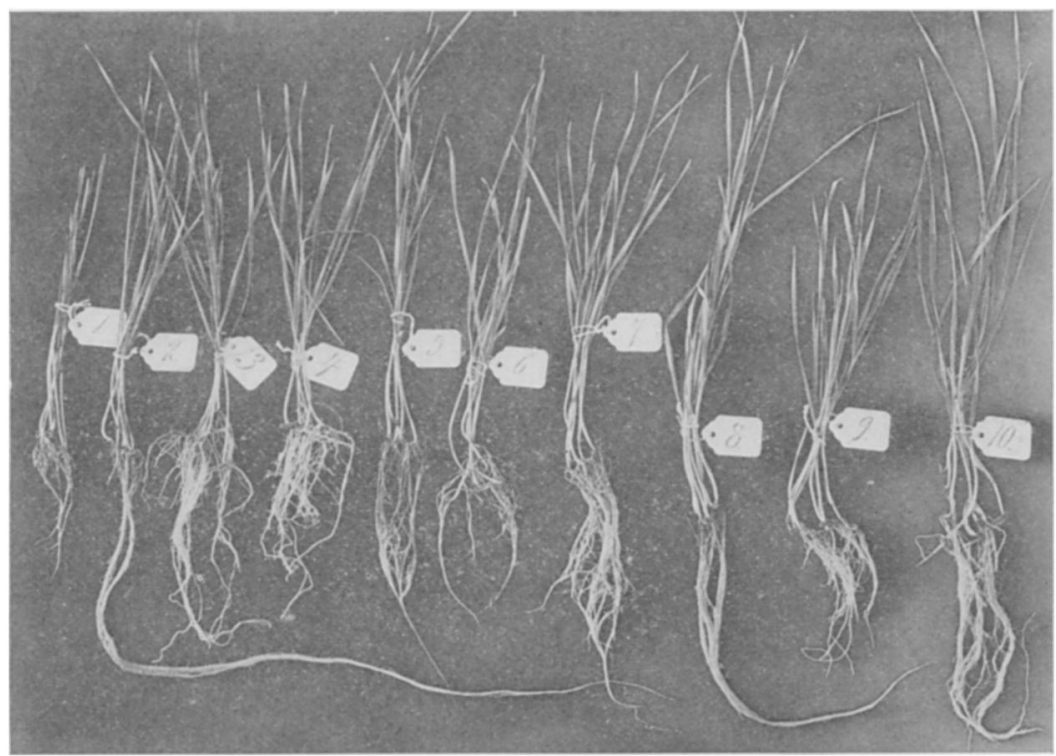

Fig. 2.-Growth of wheat plants in various cultures of bog water. Numbers as in Table V.

that the source of the harmful condition must logically be looked for in the solution and not in the condition of the plants themselves. The difference in the tops as well as in the roots of the plants from the various cultures is very striking. The stimulation effect is less marked in the solutions filtered through clay and humus, because of the greater adsorptive power of these substances; yet the increase in the green and dry weight of plants is relatively twice that in the untreated bog water while transpiration has increased almost tenfold. The introduced materials have had their adsorptive action, but it is evident 
also that chemical reaction enters in the case of the common types of garden soil.

We come finally to a consideration of the effects of bog toxins upon soils. It is to be noted that the poisonous action of bog toxins is more harmful when the plants are immersed in the solution, than when grown in the contaminated soil cultures. That the poisonous matter injurious to plant growth is present in the soils used as filters is seen upon comparison with the controls. Manifestly, the theory of lack of $\mathrm{O}_{2}$ in bog water or in bog soils as the cause of xerophily is not satisfactory to account for the results, because water cultures usually have less $\mathrm{O}_{2}$ than any soil medium. The transpiration data for boiled bog water (Table I, page 393) are further evidence in this direction. The inadequacy of the theory of low substratum temperature is, for this locality, equally obvious. That the action cannot be attributed to large amounts of dissolved substances has been shown in the determination of the osmotic pressure of bog water in the author's earlier paper (l.c.5). The garden soils contain a much larger amount of nutrient ingredients than bog water, and hence the presence of those salts should tend to increase the growth-rate. No such increase in activity occurred. The length of time during which the wheat plants were allowed to grow is palpably insufficient to "exhaust" or contaminate the soils. The retardation seen in the contaminated soils is lacking the corresponding normal average in dry weight of plants to an amount of 18 per cent., 3 per cent., and 36 per cent. for quartz, clay, and humus respectively. From the results it may be concluded that the adsorption and retention capacity of soil for toxins is generally higher the greater its content of humus. It was shown elsewhere that a bog-water solution well aerated, or upon long standing with exposure to air, lost its injurious properties. When plants are grown in this oxidized solution it is found that the solution becomes decidedly beneficial to plant growth. These results are also obtained with the contaminated soils. When first used they exert a distinctly injurious effect. If the amount of water transpired by the plants is replaced by bog water, the soils become more toxic. Decrease in toxicity always follows aeration of the soil and drainage; and since the physical conditions mainly determine the amount of oxidation, these are of greater consequence in restoring the fertility to the soil. 


\section{SUMMARY}

The available information of the study here reported may be summarized as follows:

I. Many swamp and muck soils exhibit a sterility which cannot be remedied by drainage or by the addition of fertilizers.

2. The sterility appears to be most marked where investigations on the physiological properties of bog water and bog soils indicate a greater amount and activity of bog toxins.

3. The production of bogs toxins is due to a number of physical and chemical factors. One can only conclude that the chemical constitution of bog water and bog soils at a given moment conditions toxicity; and that the excretion from roots and rhizomes of plants is one of the variables of the conditioning factors.

4. In untreated bog water there are found deposited upon the roots of wheat plants numerous colored bodies as the result of the oxidizing action of roots. The general decay of the root-tips indicates that the oxidizing activity is insufficient to decrease the harmful effects of bog toxins.

5. It is possible that ecesis, association, and succession of plants depends primarily upon respiration, and that in respiration bog plants differ from other plants.

6. Treating bog water with an insoluble adsorbing agent is invariably beneficial.

7. Different physiological phases result from the progressive addition of an adsorbing substance. With coarser-grained materials the low optimum rate of transpiration is soon succeeded by a minimum which is due to the action of toxic substances still present.

8. Finer-grained insoluble bodies are more beneficial. The response to toxic bodies when present in small amounts leads to acceleration of growth. The period of growth is more prolonged, and the optimum and maximum rate of transpiration lie near together.

9. The adsorptive action of carborundum and humus is about four times greater than that of quartz; the capacity of soils for retaining toxins is therefore higher the greater the content of humus.

Io. The decrease of the poisonous effect of bog water is probably a function of the surface of the particles; it is relatively proportionate to the quantity of the solid body used. 
II. In agricultural soils used as adsorbents the presence of the adsorbed unknown toxins replaces normal growth by an abnormal retardation. Fertility is restored through aeration, that is, after time enough has elapsed for the oxidation of the injurious bodies.

I2. The contaminated condition of agricultural soils and the consequent decreased physiological activity of the plants grown in them still further indicates that xerophily cannot be due to acidity, lack of oxygen, low temperature, etc., of the soil substratum; that is, the factors heretofore cited are only in part the cause of xerophily.

In view of the evidence presented above, the writer believes that these facts in the action of bog water upon soils justify the conclusion that there are present in bog water and in bog soils injurious substances which are, at least in part, the cause of xerophily in plants, and of decreased fertility in bog soils.

Grateful acknowledgment is made to Professors MCCALL and VIvIAN, of the Agricultural College of the university, for the facilities of their laboratories, which were freely and courteously placed at the writer's disposal.

OHio State University

Columbus, Oнiо

\section{LITERATURE CITED}

I. Blackman, F. F., Optima and limiting factors. Annals of Botany 19:28I. 1905.

2. BRIGGS, L. J., On the adsorption of water vapor and of certain salts in aqueous solution by quartz. Am. Jour. Phys. Chem. 9:6I7-640. I905.

3. Comey, A. M., Dictionary of chemical solubilities. $\mathbf{8} 896$.

4. Clark, F. W., The data of geochemistry. U. S. Geol. Survey, Bull. 330. I908.

5. Dachnowski, A., The toxic property of bog water and bog soil. Bot. Gazette 46: r30-r43. I908.

6. Hall, A. D., Theories of manure and fertilizer action. Science N. S. 28 : 6I7-628. I908.

7. Hopkins, C. G., and Pettit, J. H., The fertility in Illinois soils. Ill. Agri. Exper. Stat. Bull. I23:25I-255. I908.

8. Huston, H. A., and Bryan, A. H., Swamp muck. Rept. Ind. Agri. Exper. Stat. I900.

9. KING, F. H., Toxicity as a factor in the productive capacity of soils. Science N. S. $27: 626-635$ ، 1908 . 
Io. Livingston, B. E., Further studies on the properties of unproductive soils. U. S. Dept. Agri., Bureau of Soils, Bull. 36. I907.

II. Patten, H. E., ANd Gallagher, F. E., Absorption of vapors and gases by soils. U. S. Dept. Agri., Bureau of Soils, Bull. 5I. Igo8.

I2. StokLASA, J., UND ERnSt, A., Beiträge zur Lösung der Frage der chemischen Natur des Wurzelsekrets. Jahrb. Wiss. Bot. 46:55-102. I908.

I3. True, R. H., ANd Oglevee, C. S., The effect of the presence of insoluble substances on the toxic action of poisons. Bот. GazeTte 39: I-21. I905. 